\title{
Trajectories to abortion and abortion-related care: a conceptual framework
}

\author{
Ernestina Coast ${ }^{1}$, Alison Norris ${ }^{2}$, Ann Moore $^{3}$, Emily Freeman ${ }^{1}$ \\ ${ }^{1}$ London School of Economics and Political Science, ${ }^{2}$ Ohio State University, ${ }^{3}$ Guttmacher \\ Institute
}

\section{Working paper}

Prepared for the International Seminar on Decision-making regarding abortiondeterminants and consequences, organised by the IUSSP Scientific Panel on Abortion Research in collaboration with the Strengthening Evidence for Programming on Unintended Pregnancy (STEP UP) Research Consortium, Nanyuki, Kenya, 3-5 June, 2014

Date of last revision: July 2014

DO NOT CITE WITHOUT AUTHORS' PERMISSION 


\begin{abstract}
This paper presents a conceptual framework which captures the macro-environmental and micro-level contexts and processes of a woman's pathway to terminating her pregnancy or seeking abortion-related care. The framework has global applicability, across legal contexts and safety spectra. It can be applied at all points in the reproductive lifespan and all marital statuses. The purpose of this framework is to identify and specify the most salient aspects of abortion decision-making across populations. Social scientists as well as policy and programme planners can use the framework to highlight aspects of the macro/micro environment that facilitate or hinder women's abilities to terminate unwanted pregnancies safely and in a timely manner.
\end{abstract}




\section{Introduction}

A conceptual framework is a mechanism for organising evidence, research design and methods. Here, we describe a conceptual framework for the study of trajectories to induced abortion. Induced abortion is also referred to as termination of pregnancy (ToP) and we use both terms interchangeably throughout this manuscript. In this paper we offer:

1. justification of the need for a conceptual framework to study abortion decisionmaking trajectories;

2. description and justification of the processes leading to the development of the conceptual framework;

3. explanation, with examples, of the structure and components of the conceptual framework; and

4. reflection on the limitations of the conceptual framework.

The framework is intended to help researchers studying trajectories of abortion-related decision-making and care-seeking to consider the various contexts and processes involved in order to advance and guide future work in this area. The contexts and processes outlined in the framework are also intended to be useful for policy and programme planners in designing points of intervention.

This work complements and extends existing conceptual frameworks developed to understand postabortion complications (Banerjee and Andersen, 2012) and the intermediate outcomes of a safe abortion programme (Benson, 2005). Our framework, focused on trajectories to seeking abortion and related care, employs a wider lens than previous frameworks: we consider a diverse range of social and legal contexts, we encourage evaluation of the macroenvironment to the individual experience, and we include a broad time line from prepregnancy to post-abortion sequelae.

\section{The purpose(s) of a conceptual framework}

At its simplest, a conceptual framework is a set of broad ideas, presented in a structured way (Reichel and Ramey, 1987) intended to help us understand specific aspects of social phenomena. The conceptual framework we present here is designed to comprehensively describe the potential components of, and interactions in, a trajectory of abortion-related 
decision-making and care-seeking. In sum, it is our proposition of "the main things to be studied - the key factors, concepts, or variables - and the presumed relationships between them" (Miles and Huberman, 1994 p.18)

It is our intention that the conceptual framework is sufficiently robust and flexible to identify the key issues and relationships between them in trajectories of abortion-related behaviour and care. To this end, the framework is not constrained by concepts that have been or can be defined and measured. For example, we include emotions about pregnancy, raising children and abortion, none of which have an agreed definition or measurement scale but are nevertheless critical components in abortion-related decision-making and care.

Conceptual frameworks can have a number of purposes: to summarise and integrate knowledge, act as a reference point; establish the boundaries for a particular topic; set out focus point(s) and content, generate hypotheses, and/or articulate the pathways by which intervention/s might be expected to impact an outcome, along with others. In seeking to achieve these goals with our framework, it is our intention that it must be continually "scrutinised and tested, reviewed and reformed" (Smith, 2004) in light of new data and analyses. Presentation of the conceptual framework in this IUSSP Working Paper forms part of this scrutiny, testing, review and revision: we invite, and welcome, feedback from readers.

\section{State of the art on decision-making and abortion}

Abortion is a common feature of the reproductive lives of women globally, and unsafe abortion continues to be a major public health problem (Lohr et al., 2014). However research on abortion is challenging, particularly in settings where abortion is illegal and/or highly stigmatised (Gipson et al., 2011). This difficulty is reflected in the small volume of social science research on abortion to the relative import of the issue on the lives of women and their reproductive experiences. Decision-making processes regarding pregnancy resolution and abortion are insufficiently documented and poorly understood. In order to design policies and services to meet the needs of girls and women, we need to understand better how they navigate abortion procurement (whether safe or unsafe, illegal or legal). The evidence-base on trajectories to abortion decision-making and procurement is small and relatively recent (Banerjee and Andersen, 2012, Banerjee et al., 2012b, Schwandt et al., 2013). The International Seminar on Decision-making regarding abortion - determinants and 
consequences, organised by the IUSSP Scientific Panel on Abortion Research in Nanyuki, Kenya, 3-5 June, 2014 (hereafter, IUSSP Seminar) was a response to this under-researched field, and there is increased demand for research that can inform abortion-related policy and practice (Guttmacher Institute and Ibis Reproductive Health, 2013). We develop our conceptual framework in order to encourage a more systematic and holistic approach to the study of trajectories to seeking abortion and abortion-related care.

\section{The process of framework development}

This conceptual framework arose out of participation in the IUSSP Seminar. Twenty-four research papers were presented at this seminar, after which we presented a draft conceptual framework at the seminar's closing plenary. In order to increase the credibility of the framework as a tool, feedback from workshop participants $(n=30)$, all of whom were expert in the field of abortion research and represented a range of disciplinary and geographic perspectives, was invited. Reflections and suggestions made by IUSSP Seminar participants were incorporated into an earlier version of the framework.

Subsequently, we identified examples from the literature to test the framework's applicability and increase its specificity. After several iterations building on the initial workshop presentation, we constructed a framework involving three layers of abortion decision-making:

1. international, national and sub-national contexts;

2. individual contexts;

3. an individuals' pregnancy termination related experiences, ordered as a timesequence from sex to abortion sequelae.

These three components are presented as horizontal layers, from the macro (at the base) to the micro (towards the top), with thematic components within each level (represented in blocks) (Figure 1). 
Figure 1: Conceptual framework to understand women's trajectories to abortion and abortion-related care

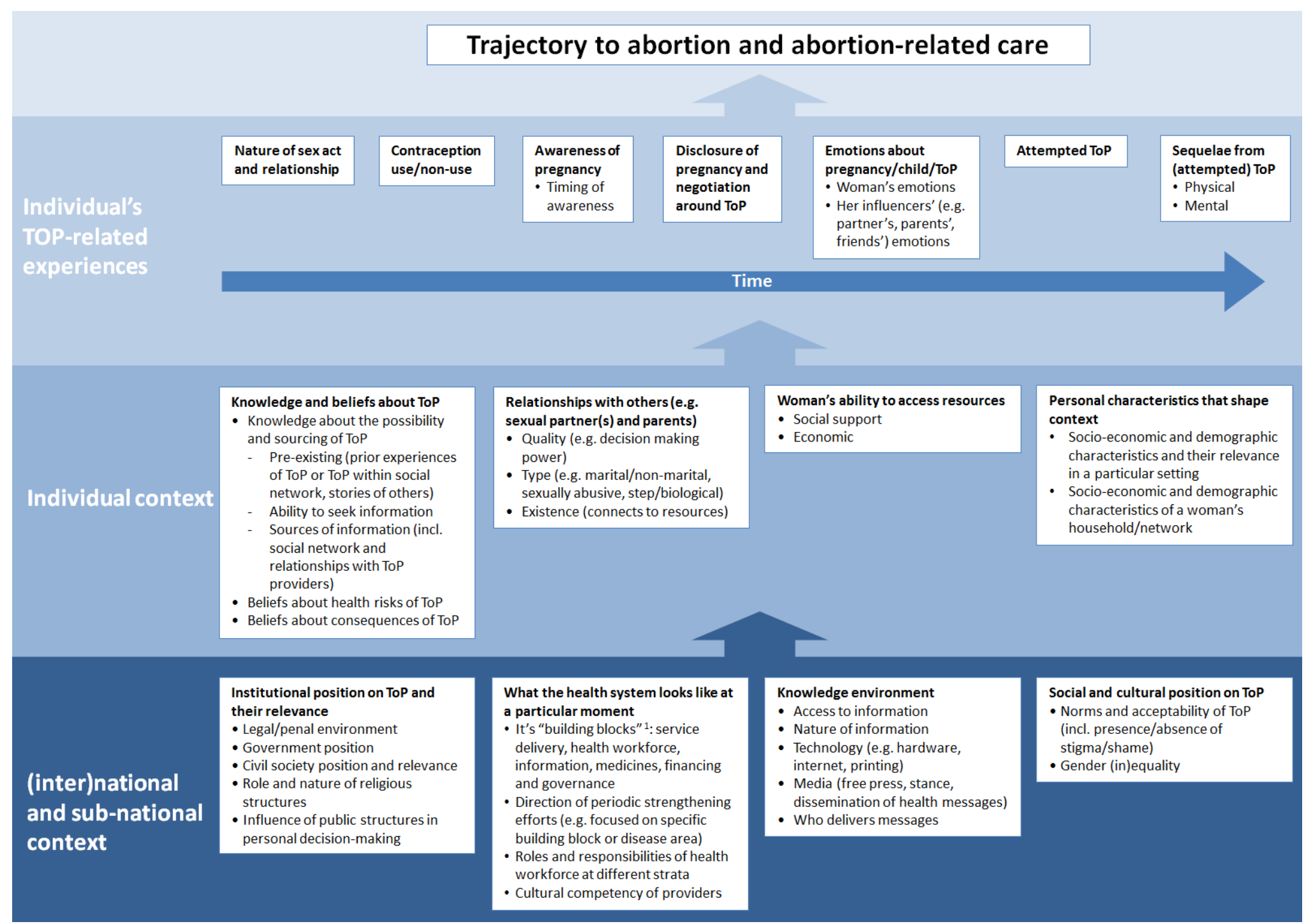

${ }^{1}$ World Health Organization (2007) Everybody's Business: Strengthening Health Systems to Improve Health Outcomes: WHO's Framework for Action. Geneva: World Health Organization 


\section{(INTER)NATIONAL AND SUB-NATIONAL CONTEXT}

In our conceptual framework to understand a woman's pathway to terminating her pregnancy or seeking abortion-related care we begin with describing the international, national and subnational (e.g.: urban-rural or state-level) context that sets the stage for decision-making. This context determines the legality of abortion and the punishments to those who violate the law, the provision and availability of safe abortions procedures, and the flow of information around abortion services. We describe these macro-level influences one by one.

\section{Institutional position on termination of pregnancy (ToP) and their relevance}

This set of factors deals with institutions (political, governmental, religious, civil society) at a range of scales (global, regional, multilateral, nation state, sub-national). The influence of these various institutions on other institutions, and the relevance of each institution's position on the termination of pregnancy (ToP) are typically interwoven. For example, the position of a given government with respect to ToP is likely to influence both law (e.g. reform), the voice of civil society (e.g. extent to which parties are in opposition or working together or the extent to which civil society is permitted a voice in debates), as well as the nature of health and/or pro/anti-natalist messages, provision of services, and economic and normative (dis)incentives towards childbearing.

\section{Politico-legal environment}

The politics including the policy environment of a specific location (country if the country has the same abortion law applying to the whole country such as Malawi, or state if there are varying laws dictating abortion availability within a country such as Mexico or the United States of America) will determine the legal as well as the penal position on abortion. The legal position is often specified in a law, a court decision (e.g. Mexico) and/or a penal code (e.g. Rwanda) (Sánchez Fuentes et al., 2008, Adeleke, 2012, Althaus, 2000, Basu, 2009, Billings et al., 2002, Darney et al., 2014, Gebrehiwot and Liabsuetrakul, 2009, Lamas and Bissell, 2000, Moore et al., 2013). Sometimes these documents are contradictory. In rare instances abortion is addressed in a country's constitution (e.g. Kenya and under discussion in Zambia). 
Some countries do not specify gestational limits on legal availability of abortion (e.g. Vietnam and China) while many others do (e.g. Bulgaria and Denmark). Language of the legal availability can be specific, such as in India where abortion cannot be performed after 20 weeks gestation, but it may also be more vague saying that abortion cannot be performed after viability (such as in the USA); with ever-improving medical technology, when viability begins is constantly shifting. Certain countries that allow abortion to be legally provided under specific conditions specify that abortion cannot be self-induced, while many countries do not take a stand on this. In addition, laws vary hugely around which pregnancy circumstances make abortion permissible: for example, in some settings abortion is permitted when the pregnancy poses a risk to a woman's physical or mental health while in others abortion is only permitted if a woman's life must be in danger. The legal landscape is further complicated by who is permitted or obligated to provide approval of these exceptions. It is often the case that multiple doctors have to certify an abortion for it to be provided legally (e.g. Uganda and Rwanda). In other countries, multiple doctors only have to certify secondtrimester abortions (e.g. India). In some instances, doctors only have to certify abortions for certain circumstances (mental disability) at any gestation. In many settings the complexity of abortion laws reverberates through society and policy makers, providers, and public alike often hold extensive misinformation about the regulations and laws surrounding abortion.

The accessibility of abortion-inducing drugs misoprostol and mifepristone is not necessarily correlated with the legality of abortion in any given country. In some countries where abortion is illegal, misoprostol is available for treatment of postpartum haemorrhage, and is distributed in mother-baby packages to women who may not be able to make it to a health facility to deliver. Its abortion-inducing properties have become well-known enough that women share it/sell it to others seeking abortion (e.g. Zambia). Accessibility of the drugs may be largely dependent upon whether it is included in the list of drugs stocked in public facilities and provided through the national government. In some places where abortion is highly restricted, the drugs are stocked in public facilities and they may be getting used for abortion. In other places where abortion is more liberally allowed, the drugs may not be allowed to be imported and accessibility is therefore greatly restricted. Informal trafficking of the drug is also widespread in some settings (e.g. Brazil, Mexico). 
Politico-legal environments may extend beyond a country's jurisdiction. International funding for governmental and non-governmental organisations has been tied to donor country's position on ToP, regardless of local legal context. For example, the 'Mexico City Policy' enacted by the USA government in 1984 specified that funding be withheld from any government and non-governmental organisations performing or promoting abortion services. Since many developing countries rely on international funding to underpin their healthcare system (including reproductive healthcare), the implementation of this restriction resulted in a reduction in abortion provision in developing countries even when abortion may have been legally provided otherwise.

\section{Penal environment}

The legal position on abortion is quite distinct from the penal position. There can be punishments specified for providers and punishments specified for women. In some places where abortion is not allowed, punishment for providing abortion or obtaining an abortion is not specified. In other places where it is specified, it is not enforced or it is enforced unequally (e.g. Mexico or Nigeria). In some places, transporting a woman for the purposes of obtaining an abortion is punishable by law (e.g. Ireland and across state lines in the United States).

\section{Civil society}

Civil society's response to abortion and the efficacy of that response in influencing provision and uptake of abortion varies greatly. In some countries, civil society is extremely active and visible on the issue (such as in the United States and Brazil) while in other countries, sometimes due in part to women's disempowerment or lack of political voice, the participation of civil society on this issue is virtually non-existent. Depending on the contemporary provision and legality of abortion and political debates, civil society can be relatively homogenous or more polarised in its messages, campaigning both for more liberal and more restrictive laws and/or provision.

Civil society includes international non-governmental organizations (INGOs) and local NGOs and has been shown to have the power to be influential on the issue of abortion in some settings (Taracena, 2002). Marie Stopes International, a UK-based INGO, provides safe abortion services and/or post-abortion care through its private, free-standing clinics using 
local providers in over 40 countries regardless of the country's abortion laws. They do not lobby for liberalization of abortion laws but simply address a demand among women. Other NGOs, including many member associations of the International Planned Parenthood Federation (itself an INGO), provide reproductive health services including abortion, with support from INGOs in the form of capacity-building, training and funding. These NGOs often play a vocal part in advocating for women's rights to a safe abortion. The International Federation of Women's Lawyers (FIDA) is another network that plays an active role at the international as well as local levels using the legal system to attempt to improve access to safe abortion (as in Uganda and Tanzania). Local NGOs have at times benefited from international funding. For example, the Reproductive Health and Rights Alliance, a network of NGOs focused on sexual and reproductive health advocacy and delivery in Kenya (including the local FIDA chapter) has been able to coordinate their political efforts to address abortion in part through funding from international donors eager to strengthen the civil society response to abortion in that country. Communities can mobilise (and be mobilised), even in settings intolerant of ToP, to improve access to services (Coeytaux et al., 2014).

\section{Role and nature of religious institutions}

Many major religions condemn the termination of pregnancy, either completely or after a particular gestation period. The extent to which religious institutions shape the structural context of women's trajectories to abortion-related care depends on the extent to which religion influences governance within a given setting and the dominance of a specific religion or religions (and the interpretation of those) in the public life. For example, although Catholicism is quite widely understood to largely restrict induced abortion in most circumstances, the influence of the Church's teaching on national laws and policies differs across Catholic countries: in much of Catholic Latin America women's access to abortion is severely restricted while in Catholic Western Europe abortion is typically legal (Blofield, 2008). Even in settings in which religion and governance are not strongly linked, religion can exert a structural-level influence on access to abortion-related care as major providers of free or affordable healthcare (e.g. mission hospitals) or through owning health care companies which as a policy may refuse to provide (or reimburse for) abortion.

Regardless of national-level influence, religion can influence local and personal structures through its teachings and messages on abortion, delivered through sermons and preaching as 
well as through the way that women who have abortion are treated within the religious community or institution. These messages form the sociological landscape of information about and attitudes towards abortion so that some women may not avail themselves of services (or choose unsafe services in the hopes that their abortion will less likely be discovered) (Frohwirth et al., 2014).

\section{Health system}

In this framework, we conceive of the health system, the site where abortion is provided (whether self-induced or provider-induced, un/safe or il/legal), as composed of the infrastructure as well as the collection of health information and investment in formal training. Parts of the health sector are dependent upon governmental funding as well as international donations to be able to train, build and maintain the health infrastructure (clinics staffed with providers who have the necessary training and equipment to provide abortion under sanitary conditions). Who is legally allowed to provide abortions also determines access to safe abortion. Places where only obstetric/gynaecologist physicians are allowed to provide abortion have a much more restrictive health environment than countries where taskshifting has occurred and nurses and other midlevel staff have been given the right to provide abortion (either through medication only or also through surgery) (Gomperts et al., 2008, Gomperts et al., 2012, Gomperts et al., 2014, Patel et al., 2009).

Whether providers are willing to provide abortion also determines abortion availability (Aniteye and Mayhew, 2013, Chavkin et al., 2013, Morhe et al., 2007, Okonta et al., 2010). Even though South Africa legalised abortion broadly in 1994, it has suffered from a consistent understaffing of providers willing to provide. Some countries allow providers (medical doctors as well as pharmacists) to formally register as conscientious objectors (Global Doctors for Choice (GDC), Harries et al., 2014). Even if they are willing to provide care, health provider's punishing attitudes and punitive treatment of women seeking abortion and/or postabortion care may influence women's willingness to avail themselves of health services. Lack of confidentiality due to lack of space or lax provider attitudes towards it may also prevent women from seeking safe services or follow-up care from an induced abortion (Jewkes et al., 2005, Marlow et al., 2014). 
The formal health system is just one site where women access abortion. In some settings lessregulated health practitioners, such as public sector practitioners who also have private clinics at their homes, herbalists, traditional birth attendants and chemists, play a larger role in the provision of abortion-related care. For example, in rural Cambodia the deep abdominal massage performed by yay mop (traditional midwives) is considered a reasonably reliable form of abortion (Hukin, 2012), in Nepal indigenous medicine provided by herbalists is commonly used (Singh et al., 1997), while in Central Eastern European and Central Asian countries such as Moldova and the Russian Federation, many women seek unregulated abortions performed clandestinely within or outside of medical facilities despite legal provision and a well-developed network of facilities (Hodorogea and Comendant, 2010).

These practitioners may be untrained (or undertrained) in providing safe abortion or may lack the necessary equipment or drugs (such as anaesthetic) to provide safe abortion. Some provide procedures that may not fully terminate a woman's pregnancy and/or may result in complications that include death. Women may choose to use unregulated providers or the unregulated services of regulated providers because they may be more easy to access, they may have greater confidence in the methods used by those types of providers, they may be unaware of alternative safe providers and/or they may not be able to afford any other services, to name but a few of the reasons.

\section{Knowledge environment}

This component of our framework reflects the importance of health knowledge-sharing norms, differential access to knowledge (e.g. by education, class, ethnicity), availability and types of knowledge-sharing technologies, and the effectiveness of knowledge-delivery systems (Kavanaugh et al., 2013a). The information environment determines women's knowledge about the legality of abortion and its restrictions, cost of abortion, the possible dangers of violating the law, and where to obtain an abortion. In legal contexts, it's possible to open a telephone or online directory and look under the word "abortion" to find a safe abortion provider where one lives. However, while there is a great deal of information available, it is not always easy to identify the ideological-motivation of some facilities. In the USA for example, a woman seeking abortion might contact a 'pregnancy crisis center' whose 
aim is to convince women to carry a pregnancy to term, and therefore become unsure of the options available to them and how to access legal abortion.

The media also plays a role in determining how the issues of abortion are portrayed (ValaHaynes and Rochat, 2007). When the media highlights vocal anti-abortion activists or the stories of children orphaned by women who die due to unsafe abortion complications, this shapes, in part, the perception of the issue of abortion. The amount of time and space dedicated to the issue, the relevant issues highlighted, the voices which are given space in the media, the language used by the media and the freedom of the media to challenge institutions that shape provision of TOP and sexual and reproductive health services, all contribute to determining how the issue of abortion is viewed in the public eye.

\section{Social and cultural position on ToP}

Norms about, and acceptability of, ToP - including the presence/absence of abortion-related stigma and shame - affect the framing and experience of ToP for individual girls and women (Macleod et al., 2011, Norris et al., 2011). Operating in parallel and influencing social and cultural positions on ToP are norms and experiences of gender (in)equality.

Gender, that is, the construction of gender roles specifically as relates to sexual activity and women's prescribed roles in society, is not static in a region or country. Gender expectations may be ethnically and socioeconomically determined with a country and it may vary over the life course (Agadjanian, 2005). Abortion can hide unsanctioned sexual activity (e.g. before marriage, extramarital) and so to the extent that a given society is invested in punishing those who betray sexual norms, abortion is a threat to that social order. Other legal restrictions such as waiting periods (in the United States) or husband's consent (sometimes legally specified and sometimes a form of social sanctioning) signify a lack of social confidence in women's decision-making authority. It must be remembered that the stigma associated with abortion may not be only stigma directly against the act of having abortion itself but also about the rejection of motherhood and perhaps against women's sexual activity as well.

In a gender framework, women who have abortions are loose women whose lack of sexual restraint makes them less socially valued which justifies stigma and shaming. Women may 
watch others in their community be stigmatised from an abortion experience and take that information into consideration when weighing their options of what to do with an unintended pregnancy. They may also hear stories in the media which portray women who have had abortions negatively. Social narratives around abortion may serve to further reinforce the social undesirability of not only the act of abortion but also women who have abortions (Chełstowska, 2011, Geary et al., 2012, Kavanaugh et al., 2013b, Levandowski et al., 2012, McMurtrie et al., 2012, Orner et al., 2011, Orner et al., 2010, Payne et al., 2013, Shellenberg and Tsui, 2012, Tagoe-Darko, 2013, Boateng, 2013). In some settings, while abortion might be normatively shameful, it is perceived as less shameful than a mis-timed pregnancy (Johnson-Hanks, 2002).

Aside from direct enacted or threatened stigma, the roles and opportunities afforded to women through educational as well as professional avenues are important social contextual for how women, and society, views abortion. In contexts where women have important roles in civic society and opportunities for work and education, women and men may be more supportive of access to legal abortion. Likewise, when women have more life opportunities, the opportunity cost of an unwanted pregnancy may be greater, making abortion a more desirable path. Potentially if opportunities for women are constrained (or non-existent), the opportunity costs of not having an abortion are much lower and abortion may not be as desirable an outcome.

In some settings, these beliefs are extended to non-physical realms. An ethnographic study in rural Ghana of the Ewe ethnic group used participant observation and informal conversations in order to understand the ways in which women navigate cultural and religious norms when procuring a termination. In this study, women's bodies are presented as "social bodies", embedded in multiple sets of relationships (physical and ancestral), subject to social regulation, and not always her own to do with as she would wish (Webster, 2013). Women who undergo an abortion therefore not only consider the contemporary physical and health risks in their decision-making to abort, but also balance these against potential risks to their position within their society and communities and in this setting, in their afterlife.

\section{INDIVIDUAL CONTEXT}


This level of the conceptual framework deals with the socio-demographic characteristics, knowledge and beliefs, relationships and resources of an individual woman, each of which will not only interact with each other (e.g. younger women are less likely to have access to financial resources to pay for a safer termination), but also with the (inter)national and subnational context with which she is situated.

\section{Knowledge and beliefs about ToP}

Knowledge and beliefs about ToP include not only knowledge about the possibility and sourcing of ToP, but also beliefs about the potential consequences of procuring an abortion. A hospital-based qualitative study in Cameroon conducted 65 in-depth interviews with women against a context where abortion is highly restricted and only legally available in cases of rape. Despite an overwhelming imperative to keep an abortion secret, women's need to end a pregnancy for economic and social reasons, overrode fears of potential complications (Schuster, 2005). This need for secrecy increased the health complications of the terminations that were conducted.

For some individuals, pre-existing knowledge about the possibility and sourcing of ToP might be central to influencing the trajectory that she follows. She might have prior experience of ToP herself, or might have been exposed to narratives about ToP from within her familial or social networks. For example, in a study of 1411 poor married women in India who had limited exposure to mass media, women who had knowledge about abortion from family, friends or community health workers were more likely to perceive that services are available and have positive attitudes toward abortion (Banerjee et al., 2012a). Similarly in Uganda where abortion is illegal unless to save a woman's life, women reported that friends were their most import source of practical advice about how to terminate an unwanted pregnancy, especially in rural areas (Jagwe-Wadda et al., 2006).

Knowledge and beliefs within an individual's social network may also be a barrier to accessing ToP services. In a study of women's experiences of accessing abortion services and information in Malaysia, a setting with relatively liberal abortion laws, women reported that the main barriers to accessing care had been a lack of information. Most had obtained 
information about abortion and available services by asking friends or colleagues, but noted that this was often superficial and inadequate and that information obtained through the media was rare (Tong et al., 2012). In a hospital-based recruitment of women seeking an abortion $(n=100)$ in Nigeria, of the $48 \%$ of respondents who had attempted to terminate using drugs, very few had accurate information about safe drugs and doses (Adinma et al., 2012). In a study of men's roles in determining women's access to abortion in Ugandan, men reported that the importance of lineage among some of the ethnic groups was so strong that for some, it is inconceivable to abort a foetus conceived within particular blood lines (Moore et al., 2006). A South African study explored why South African women still abort outside designated services where there is substantial legal service provision. Amongst those women who knew that safe and legal ToP services were available, significant proportions did not use these services because of perceptions about staff rudeness and anticipated breaches of confidentiality (Jewkes et al., 2005).

\section{Relationships with others}

Across various cultural settings, for some women, the decision to abort and subsequent abortion procurement are taken alone (Bowes and Macleod, 2006). For other women, the role of others (partners, families, friends, service providers) can be critical in decision-making and in the access to information and services. The quality (e.g.: decision-making power), type (e.g. marital/non-marital, sexually abusive, step/biological, commercial) and existence of relationships with others can explain and/or mediate decision-making and any subsequent actions (Aniteye and Mayhew, 2011, Mpangile et al., 1998, Ralph et al., 2014, Ramachandar and Pelto, 2002, MacQuarrie et al., 2007). A study conducted with women after their abortions $(n=50)$ in Ghana underlines the range of roles played by men in abortion-related decision-making. The roles ranged from direct "orders" to abort to indirect influence by denying pregnancy paternity. While ToP is legal in Ghana, few government health care facilities provide abortion services, and those that do, do not publically advertise these services (Schwandt et al., 2013). In a qualitative study of the experiences of unmarried females aged 10-24 ( $n=34)$ who obtained ToP at a government facility in India, 26 of 34 terminations were sought at $\geq 12$ weeks gestation. The research sought to understand the reasons for the delay in ToP care-seeking and identified fear of disclosure, lack of support and 
lack of economic resources to be important factors. In 30 of the 34 cases, the decision to terminate involved other family members, particularly the mother (Sowmini, 2013).

\section{Ability to access resources}

Women's ability to access social and economic resources is important in every geographic setting (Zamberlin et al., 2012, Lafarge et al., 2013, Bowes and Macleod, 2006, Schwandt et al., 2013). A computer-administered survey of women $(n=639)$ obtaining abortions across 6 US-based facilities (Jones et al., 2013) found that of those women who did not use insurance for their abortion, over half (52\%) found it difficult to pay for the procedure and had to rely on (an)other to help pay costs (transportation, lost wages, childcare) - particularly the man involved in the pregnancy - or had to delay the payment of other bills (rent, food) to pay for the abortion. A political economy analysis of the costs of abortion in India, where ToP is legal, showed that the costs to women are determined largely by supply-side factors (Duggal, 2004). The cost of abortion in India varies considerably, depending on the number of weeks of pregnancy, the woman's marital status, the method used, type of anaesthesia, whether it is a sex-selective abortion, whether diagnostic tests are carried out, whether the provider is registered and whether hospitalisation is required. Abortions in the public sector in India are free only if the woman accepts some form of contraception; and, other fees may also be charged. An assessment of abortion outcomes and costs to the health care system in Mexico City was conducted in 2005 at a mix of public and private facilities prior to the legalisation of abortion (Levin et al., 2009). Direct cost estimates (e.g.: personnel, drugs, disposable supplies, and medical equipment for inducing abortion or treating incomplete abortions and other complications) and indirect patient costs (e.g.: travel, childcare and lost wages) were estimated. Average costs varied significantly depending on the type and provider of the ToP; medical abortion with misoprostol alone was US\$79 compared to US\$143 for dilatation and curettage. Ability to access resources is in itself a potential function of gender (in)equality.

\section{Personal characteristics that shape context}

The socio-demographic characteristics of women (age, wealth, education, residence, marital status, parity, etc.) will operate to influence every aspect of her trajectory, and be influenced by the socio-cultural setting within which she lives (Edmeades et al., 2010). A woman's 
individual characteristics shape or mediate all other issues, including economic power, decision-making power, and access to knowledge. The influence of personal characteristics will, in turn, depend on the context. For example, being female means something different for access to health information and services in the UK than in Pakistan; being married has different implications for decision making power in Malawi and Saudi Arabia. A multi-site study in Vietnam interviewed women $(n=1224)$ about repeat $(\geq 2)$ abortions (Ngo et al., 2014). Factors identified as significant in predicting a repeat abortion included place of residence, higher parity, age 35 years or older, and an imbalance in the sex of existing children (having 2 or more daughters or no sons). The socio-cultural context, which underscores son preference, is identified as an important predictor of repeat abortion in this setting. This example underscores the interconnectedness of the different levels of our conceptual framework.

The influence of socio-demographic individual-level characteristics on women's knowledge is also underscored at the aggregate level. Statistical analysis of survey data from Ghana investigated individual and household-level factors associated with report of pregnancy termination. After controlling for individual demographic characteristics (age, education, place of residence), increasing autonomy was significantly associated with the likelihood of reporting a ToP (Rominski et al., 2014). Statistical analyses of register data on Finnish women in three birth cohorts $(1955-59,1965-69,1975-79)$ indicated that despite a decline in the overall teenage ( $\leq 19$ years) pregnancy rate, teenagers who came from wealthier backgrounds had 2-3 times the odds of abortion(Väisänen and Murphy, 2014).

In settings with recent changes in abortion legislation, aggregate analyses reveal sociodemographic disparities in knowledge. Analyses of the Nepal DHS (2006 and 2011) following recent liberalisation of the abortion law in Nepal show an overall improvement in the levels of knowledge about the law and of a place for obtaining abortion services (Thapa et al., 2014). However, these increases in overall knowledge levels were significantly associated with being from higher wealth quintiles and/or higher levels of educational attainment. The relationships are not, however, simple. A pre- and post-study design of an intervention delivered through a combination of information provision by community intermediaries and a behaviour change communication programme to increase knowledge about abortion legality and service provision in India, where despite ToP legality since 1972, levels of knowledge 
and services were low, found that intervention exposure led to significant increases in knowledge about legality and gestational age limits of ToP (Banerjee et al., 2014). However, only interpersonal communication was associated with a significant increase in knowledge about safe services. Safe abortion service use at earlier gestational age was reported postintervention.

\section{INDIVIDUAL'S PREGNANCY TERMINATION-RELATED EXPERIENCES}

Having considered the macro-environmental context for abortion decision-making processes, and the individual contextual factors that shape women's options, we turn now to the personal decision steps and choices than any individual woman makes on the trajectory to terminate a

pregnancy (or to attempt to terminate a pregnancy). In all instances where an abortion may be pursued, women proceed through time-ordered experiences of: sexual behaviour, contraception (non)use/failure, becoming aware of a pregnancy, (non)disclosure and negotiation, emotions about pregnancy, having a child and ToP, attempts to terminate the pregnancy, and the sequelae of those attempts. Each of these is embedded within the inter/sub/national context and the individual context of an individual woman's life. We consider each of these decision steps, providing explanation of the decisions that are made at each point, with examples from a variety of settings.

\section{Nature of sex act and relationship}

The starting place for a pregnancy is sexual intercourse. Intercourse usually takes place in the context of a relationship. The dimensions of the sexual relationship - marital status, the duration of relationship, the power differential between partners - all have implications for the likelihood that a pregnancy resulting from sexual intercourse is intended or wanted. For example, in Uganda, unmarried women are at high risk for unintended pregnancy, given exposure to sexual coercion and sexual activity without the capacity to prevent pregnancy (Guttmacher Institute, 2013).

Also important for decisions about sexual intercourse and its consequences are expectations that a woman has about the relationship: is the relationship stable and ongoing? Are future goals shared between partners? Does the woman have children with this partner already? For 
some women, a pregnancy with the 'wrong' partner is what makes the pregnancy unwanted. For example, in a study of women in the United States, nearly a third cited 'partner related reasons' for why they sought an abortion (Biggs et al., 2013).

In some circumstances, sexual intercourse is coerced or forced, in which case the step of sexual intercourse has not involved a decision or choice for the woman. The situation of coerced sex may change a woman's personal feelings about the pregnancy and about terminating it. Likewise, there are often different social and legal contexts for termination of pregnancies conceived in rape which change the macro-environmental influences on an individual woman's decision to terminate a pregnancy. In yet other circumstances, the pregnancy might be the result of commercial sex (Marlow et al., 2014).

\section{Contraception use/non-use}

Separate from the decision to have sexual intercourse, a woman and a couple have a decision point about contraception. Globally it is estimated that 80 million women have an unintended pregnancy each year, $60 \%$ of which are aborted. Around two-thirds of these pregnancies are conceived among women who are not using contraception (Grimes et al., 2006).

Contraception use is a critical aspect of abortion decision-making in the respect that by exposing themselves to the risk of pregnancy, women are then opening themselves up to the possibility of having to make decisions about an unwanted pregnancy.

The reasons for non-use of contraception are multiple, and include lack of access to or information about a method or a desired method (Uganda Bureau of Statistics (UBOS) and ICF International, 2012), partner's disapproval of contraceptive utilisation (Esber et al., 2014), and concern for side effects and health risks (Sedgh and Hussain, 2014). In many contexts, young women, unmarried women, women who have never had a child and women who are considered as reaching the end of their childbearing years may face additional barriers in accessing contraception (if they perceive health care providers will not give them contraception or there is a great deal of stigma to unmarried women's sexual activity) (Uganda Bureau of Statistics (UBOS) and ICF International, 2012), or they may simply be unable to talk about contraception or pregnancy with their partner. For example, in the study among young women who terminated pregnancies in India mentioned earlier, only two of 34 
had used any contraception at all and most had not talked about contraception in their relationship (Sowmini, 2013). Due to these social barriers some women choose to use contraceptive methods secretly, hiding from parents and/or partners. Maintaining secrecy may increase the likelihood of failure to access or use a method in a timely manner (e.g. Zambia).

Contraceptive methods have variable efficacy. A woman who decides to use an implant or IUD is least likely to conceive a pregnancy; a woman who decides to use a hormonal method (OCP, injectable) is relatively more likely to have an unintended pregnancy, and a user of condoms, withdrawal and periodic abstinence is at even greater risk (Hatcher, 2007). In addition to the efficacy of the method, a woman and a couple may have variable consistency of use. Among those who rely on condoms, withdrawal and/or periodic abstinence for contraception, a woman does not maintain singular control over the correct use of the method, and faces a higher likelihood of a pregnancy she did not intend.

\section{Awareness of pregnancy}

The decision to terminate a pregnancy is uniquely time sensitive. Other health care decisions may not cease to be an option in the span of a few months. Likewise, the safety of ToP changes dramatically in a matter of weeks. A termination early in a pregnancy is easier and safer than later in pregnancy. As the pregnancy advances, termination becomes more complicated and eventually is no longer an option. Thus the amount of time that lapses between conception and a woman's awareness of her pregnancy is critical and directly related to the amount of time she has to decide to proceed with a termination. While in developed country contexts pregnancy tests are widely available, they can be expensive. For example in the USA poorer women may access pregnancy tests at the 'pregnancy crisis centers' discussed earlier, with the concomitant complication of being provided with misinformation about abortion's risks. In other contexts they are both widely and available at no or little cost (e.g. in the UK where pregnancy tests are free at point of access from GPs, sexual health clinics, NHS walk-in centres and some pharmacies, and relatively inexpensive and available from retail shops) facilitating women's knowledge of their pregnancy. In many developing country contexts, pregnancy tests may be unavailable or unaffordable. A woman may wait 
weeks or months before concluding that she is pregnant as each missed period provides her further confirmation.

Taking action to obtain a pregnancy test is tightly linked to the social value or social risk of having a pregnancy. In contexts where a pregnancy is highly socially undesirable, a woman may avoid acknowledging to herself that she has a pregnancy, so as to avoid the consequences that such a situation will bring about (Coast and Murray, 2014, Sowmini, 2013).

\section{Disclosure of pregnancy and negotiation around pregnancy termination}

After acknowledging a pregnancy, a woman may disclose her pregnancy to other people who may help or guide her decision about terminating the pregnancy and/or arranging the abortion. This individual decision point of disclosure and/or negotiation is embedded in the woman's larger context of relationships and ability to access resources, both social and economic. Often, other people to whom a woman might disclose include the woman's male partner, her family members, and trusted confidants (Sedgh et al., 2011). The male partner may have a special role to play. For example, the male partner may be the person to discuss with the woman what will happen if she terminates the pregnancy and what will happen if she bears the child. The male partner may help with logistical arrangements for obtaining the abortion (finding a provider, getting to the provider, paying for the abortion).

In other instances, there may be discordance between the woman's plans to terminate or continue with the pregnancy and the man's desires. For example, a male partner may be against abortion, and try to obstruct the woman's efforts to terminate the pregnancy (Moore et al., 2010). In still other cases, the male partner may deny his role in the pregnancy or refuse to help the woman to obtain an abortion, leaving the woman to cope with obtaining an abortion without his assistance (Jagwe-Wadda et al., 2006).

Often disclosure involves either emotional support around the abortion decision, or emotional pressure to have an abortion or not to have an abortion. In a US-based study, for example, a majority of younger women (age 17 and younger) who were having abortions reported that their mothers and partners were involved in the abortion decision. Most young women felt that these people were supportive of their decision. A minority of women expressed that they 
were having an abortion because someone else wanted them to, with mothers being most often identified as the source of this pressure (Ralph et al., 2014). A woman's autonomy in decision-making may influence to whom she discloses her plans to terminate a pregnancy, and how she manages any negotiations in cases of discordant expectations. Therefore, it is not surprising that such a large proportion of young women sought the involvement of others in their decision-making regarding abortion.

The decisions a woman makes around disclosure are situated in the larger context of her relationship so others. These decisions are further enmeshed in the macro-environmental context which avails or constrains options for safe, affordable, accessible abortion care. The more limited the macro-environmental aspects, the more the individual woman many need to disclose her situation to others, and to rely on assistance from those with whom she has relationships (Rossier, 2007).

\section{Emotions about pregnancy/child/ToP}

A woman may have conflicting and changing emotions about the ideas of being pregnant, bearing a child, and terminating a pregnancy. These emotions are influenced by the response she receives from disclosure of the pregnancy to other people, particularly those who will participate in her decision to terminate the pregnancy or share the consequences of not terminating the pregnancy.

A woman and her partner's feelings about the pregnancy and bearing a child may be influenced by the financial situation of the woman and of the partner. In addition, the commitment of the partner to the relationship may be critical to how a woman feels about the pregnancy. In some situations, a woman may seek a pregnancy to move a relationship to a new level of commitment. If the partner's response is positive, they may marry. If, on the other hand, he denies the relationship or the pregnancy, a once-sought pregnancy may become an undesired pregnancy, and the woman may seek an abortion.

Critical to how a woman feels about a pregnancy and bearing a child are her experiences of the prevailing social norms about pregnancy and birth. As described in the (inter/sub)national contexts domain of the conceptual framework, stigma and social norms are hugely influential, 
and an individual woman will experience either that bearing a child outside of marriage is acceptable, or that it leads to her being ostracised with serious long term consequences for marriage and financial stability. Likewise, individual contextual factors will influence whether an individual woman experiences more or less autonomy to make a decision that goes against social norms.

For a woman (and potentially her partner and/or family as well) there are likely to be ongoing, significant economic and social responsibilities to raise a child. In addition to these expenses, bearing a child has short- and long-term economic and opportunity costs to the woman, particularly with respect to attending school or working. These economic realities may influence a woman's feelings about her pregnancy.

The timing of a pregnancy in the context of woman's reproductive career may be important to her feelings about a pregnancy and bearing a child. In some contexts, a pregnancy before marriage may be highly undesirable, whereas immediately after a marriage would be highly desirable. Likewise, a pregnancy with close birth spacing may be unacceptable, whereas a pregnancy with two year spacing would be considered ideal. Each woman's particular situation with respect to her reproductive career will influence whether a pregnancy is wanted or not, and whether its termination provides a better outcome for the woman than bearing a child at that time (Norris et al., 2014).

For a woman who terminates a pregnancy due to foetal abnormality, the emotions about the pregnancy and coping with its termination may be additionally complex, and may include acknowledging the 'baby', disassociating from the procedure, and attributing meaning to the birth experience (Lafarge et al., 2013). The macro-contextual factors (norms, policies, stigma) are also significantly shifted in the situation of foetal abnormality, and a woman's decision will be influenced by those.

When considering terminating the pregnancy, women's emotions may include fears about the risks of termination, anxiety about access to the procedure, and concerns about the moral consequences of terminating a pregnancy. An individual woman's experience of this will depend on her individual context (e.g. access to resources) and the macro-context (e.g. the knowledge environment). A woman may have a great deal of fear about the physical and 
emotional consequences of abortion. These emotions may be modulated by how stigmatised abortion is in her context. Emotions about abortion may be influenced as well by the expectations of the sexual partner and other individuals who are involved in the decisionmaking process. Finally, emotions about termination of pregnancy may also include concerns about legality. Thus while these are intensely personal emotional feelings, they are inextricably embedded in the macro-environment and the individual context.

A woman may decide to seek an abortion, and to keep it secret. Abortion is often covert because termination of pregnancy is stigmatised itself and also because keeping the abortion secret means protecting the secrecy of the unplanned pregnancy.

\section{Attempted ToP and Sequelae from ToP}

Once a woman has decided to try to terminate a pregnancy, she faces several decisions. She must find a way to terminate the pregnancy, which involves a choice to self-induce an abortion or find an abortion provider and (perhaps) choosing a termination method. (In some settings, a woman may not be able to find out about methods of pregnancy termination, and may simply take the only method that is provided to her.) As noted in the macro-contextual features of the framework, knowledge environment is highly variable. In contexts where abortion is legally restricted, a woman may find that information about providers and methods is not openly available; even in contexts where abortion is legal, a woman may encounter misinformation about abortion's safety and quality of care of abortion services. In many countries, a woman will have the option to choose between a surgical and a medication abortion; having the choice leads to better psychological outcomes after the abortion. Terminating a pregnancy necessitates a woman deciding to locate and in many places pay for an abortion. In some settings, a woman may have options about safety and quality of care; in others, a woman may not have any choice (Banerjee and Andersen, 2012). Where abortion is legally restricted, many women will attempt self-induction of abortion. The legal and penal environment, as well as the health care context, shape the options that an individual decisionmaker can access.

After attempting to terminate a pregnancy, a woman may experience physical consequences, emotional consequences, or both. Physical consequences for a woman may include the 
expected side effects of abortion (cramping, bleeding), and may include mild, moderate or severe complications. In settings where abortion is legally restricted, a woman may have access to safe and legal PAC services after an illegal termination. Following a complication from termination of pregnancy, a woman may experience consequences that result in long term disability (including infertility and fistula) or even death.

A woman may experience a range of emotional sequelae after a pregnancy termination. Some women experience regret for the pregnancy and/or the abortion. Others experience relief that they are no longer pregnant (Watson, 2014). In many settings globally, both in contexts where abortion is legal and illegal, women may worry about their future fertility following a termination (Moore et al., 2011).

Some women experience guilt about the abortion. Whether women experience guilt or not, most choose to keep their pregnancies and abortions secret, to hide the stigma of the socially unsanctioned sex, the unwanted pregnancy, and the stigmatised abortion. Abortion can be emotionally upsetting, but for many women it simultaneously represents a pragmatic solution to a problematic pregnancy.

\section{DISCUSSION AND CONCLUSION}

Our conceptual framework offers a point of departure for new research by drawing attention to primary components and linkages in describing and explaining women's trajectories to abortion decision-making and behaviour. In so doing, it highlights the ways in which abortion trajectories are influenced by macro- and micro-level factors that operate in multiple (and sometimes conflicting) ways. The conceptual framework that we have developed reflects the decision-making process of women in a range of contexts around the worldeconomic, social, cultural, political, and legal. Our review of the literature gives specificity to the concepts in our framework, and highlights areas of importance - and often scarce evidence - especially from settings where abortion is illegal and/or highly stigmatised. The framework pushes us to move well beyond the sorts of research that simply describes trajectories through a narrow lens. Rather, the existing research body needs to be complemented by more holistic ways of understanding the trajectories (and their influencers) 
on girls and women seeking abortion-related care to understand how abortion fits into their social circumstances and in with their reproductive careers.

\section{LIMITATIONS OF THE CONCEPTUAL FRAMEWORK}

Our framework reflects our experience and knowledge, and therefore our implicit initial biases in developing it. It reflects our empirical observation, a priori reading and intuition, alongside our need to organise our thinking about complex scenarios. We have tried to confront (but not eliminate) these biases by "testing" the framework through applying it to presentations and publications that deal with abortion decision-making and trajectories, drawn from as wide a geographic and conceptual range as possible. In constructing this conceptual framework, we remain open to unexpected and new evidence, and its potential influence to change the proposed framework.

In any two dimensional representation there are limitations to the illustration of complexity and the inter-relationships between the different levels. Our representation implies clear boundaries between the components and levels - and simplifies the complexity and messiness of trajectories of abortion decision-making and behaviours. However in our opinion they still serve as useful organisers from which to develop departure points for future research agendas and points of policy/programmatic intervention.

\section{ACKNOWLEGDEMENTS}

The authors would like to thank the IUSSP Seminar participants which form the basis for this framework. Leila Darabi provided assistance on drafting the text on the role of civil society in abortion advocacy. 


\section{REFERENCES}

ADELEKE, F. A. R. 2012. Locating the determinants of unsafe abortion beyond the legal framework of abortion laws : a case study of Nigerian and Ghanaian abortion laws. Journal of African and International Law, 5, 555-573.

ADINMA, E. D., ADINMA, J. I. B.-D., IWUOHA, C., AKIODE, A., OJI, E. \& MATTHEW, O. 2012. Knowledge and practices among medical abortion seekers in southeastern Nigeria. Southeast Asian Journal of Tropical Medicine and Public Health, 43, 471478.

AGADJANIAN, V. 2005. Fraught with Ambivalence: Reproductive Intentions and Contraceptive Choices in a Sub-Saharan Fertility Transition. Population Research and Policy Review, 24, 617-645.

ALTHAUS, F. A. 2000. Work in progress: the expansion of access to abortion services in South Africa following legalization. International Family Planning Perspectives, 26, 84-86.

ANITEYE, P. \& MAYHEW, S. 2011. Attitudes and experiences of women admitted to hospital with abortion complications in Ghana. African Journal of Reproductive Health, 15, 47-55.

ANITEYE, P. \& MAYHEW, S. H. 2013. Shaping legal abortion provision in Ghana: using policy theory to understand provider-related obstacles to policy implementation. Health Research Policy and Systems, 11.

BANERJEE, S., ANDERSEN, K., BAIRD, T., GANATRA, B., BATRA, S. \& WARVADEKAR, J. 2014. Evaluation of a multi-pronged intervention to improve access to safe abortion care in two districts in Jharkhand. BMC Health Services Research, 14, 227.

BANERJEE, S., ANDERSEN, K., BUCHANAN, R. \& WARVADEKAR, J. 2012a. Womancentered research on access to safe abortion services and implications for behavioral change communication interventions: a cross-sectional study of women in Bihar and Jharkhand, India. BMC Public Health, 12, 175.

BANERJEE, S. K. \& ANDERSEN, K. 2012. Exploring the Pathways of Unsafe Abortion in Madya Pradesh, India. Global Public Health Journal, Forthcoming.

BANERJEE, S. K., ANDERSEN, K. L. \& WARVADEKAR, J. 2012b. Pathways and consequences of unsafe abortion: A comparison among women with complications after induced and spontaneous abortions in Madya Pradesh, India. International Journal of Gynecology and Obstetrics, 118, S113-S120.

BASU, J. 2009. Legal unsafe abortion in South Africa. International Journal of Gynecology and Obstetrics, 107, S121-S121.

BENSON, J. 2005. Evaluating Abortion-care Programs: Old Challenges, New Directions. Studies in Family Planning, 36, 189-202.

BIGGS, M., GOULD, H. \& FOSTER, D. 2013. Understanding why women seek abortions in the US. BMC Women's Health, 13, 29.

BILLINGS, D. L., MORENO, C., RAMOS, C., GONZÁLEZ DE LEÓN, D., RAMíREZ, R., VILLASEÑOR MARTíNEZ, L. \& RIVERA DíAZ, M. 2002. Constructing Access to Legal Abortion Services in Mexico City. Reproductive Health Matters, 10, 86-94.

BLOFIELD, M. 2008. Women's choices in comparative perspective: Abortion policies in latedeveloping Catholic countries. Comparative Politics, 399-419.

BOATENG, M. 2013. Ghana: Health Workers Call for De-Stigmatisation of Abortion. The Chronicle, Ghana, 13 August 
BOWES, T. \& MACLEOD, C. 2006. The characteristics of women seeking termination of pregnancy at an urban-based government hospital in the Eastern Cape. Curationis, 29, $12-8$.

CHAVKIN, W., LEITMAN, L. \& POLIN, K. 2013. Conscientious objection and refusal to provide reproductive healthcare: a White Paper examining prevalence, health consequences, and policy responses. Int J Gynaecol Obstet, 123 Suppl 3, S41-56.

CHEŁSTOWSKA, A. 2011. Stigmatisation and commercialisation of abortion services in Poland: turning sin into gold. Reproductive Health Matters, 19, 98-106.

COAST, E. \& MURRAY, S. 2014. Pregnancy termination trajectories in Zambia. In: RESEARCH, I. S. P. O. A. (ed.) International Seminar on Decision-making regarding abortion-determinants and consequences. Nanyuki, Kenya: IUSSP.

COEYTAUX, F., HESSINI, L., EJANO, N., OBBUYI, A., OGUTTU, M., OSUR, J. \& SHUKEN, K. 2014. Facilitating women's access to misoprostol through communitybased advocacy in Kenya and Tanzania. International Journal of Gynecology \& Obstetrics, 125, 53-55.

DARNEY, B. G., SIMANCAS-MENDOZA, W., EDELMAN, A. B., GUERRA-PALACIO, C., TOLOSA, J. E. \& RODRIGUEZ, M. I. 2014. Post-abortion and induced abortion services in two public hospitals in Colombia. Contraception, 90, 36-41.

DUGGAL, R. 2004. The Political Economy of Abortion in India: Cost and Expenditure Patterns. Reproductive Health Matters, 12, 130-137.

EDMEADES, J., LEE-RIFE, S. M. \& MALHOTRA, A. 2010. Women and reproductive control: the nexus between abortion and contraceptive use in Madhya Pradesh, India. Stud Fam Plann, 41, 75-88.

ESBER, A., FORAKER, R. E., HEMED, M. \& NORRIS, A. 2014. Partner approval and intention to use contraception among Zanzibari women presenting for post-abortion care. Contraception, 90, 23-28.

FROHWIRTH, L., COLEMAN, M. \& MOORE, A. M. 2014. Managing Religion and Morality within the Abortion Decision: Data from Qualitative Interviews with Women Obtaining Abortions in the U.S. Population Association of America 2014 Annual Meeting. Boston, MA.

GEARY, C. W., GEBRESELASSIE, H., AWAH, P. \& PEARSON, E. 2012. Attitudes toward abortion in Zambia. International Journal of Gynecology \& Obstetrics, 118, Supplement 2, S148-S151.

GEBREHIWOT, Y. \& LIABSUETRAKUL, T. 2009. Trends of abortion complications in a transition of abortion law revisions in Ethiopia. Journal of Public Health, 31, 81-87.

GIPSON, J. D., BECKER, D., MISHTAL, J. Z. \& NORRIS, A. H. 2011. Conducting Collaborative Abortion Research in International Settings. Women's Health Issues, 21, S58-S62.

GLOBAL DOCTORS FOR CHOICE (GDC) Summary.

GOMPERTS, R., PETOW, S. A. M., JELINSKA, K., STEEN, L., GEMZELLDANIELSSON, K. \& KLEIVERDA, G. 2012. Regional differences in surgical intervention following medical termination of pregnancy provided by telemedicine. Acta Obstetricia et Gynecologica Scandinavica, 91, 226-231.

GOMPERTS, R., VAN DER VLEUTEN, K., JELINSKA, K., DA COSTA, C. V., GEMZELL-DANIELSSON, K. \& KLEIVERDA, G. 2014. Provision of medical abortion using telemedicine in Brazil. Contraception, 89, 129-133.

GOMPERTS, R. J., JELINSKA, K., DAVIES, S., GEMZELL-DANIELSSON, K. \& KLEIVERDA, G. 2008. Using telemedicine for termination of pregnancy with mifepristone and misoprostol in settings where there is no access to safe services. BJOG: An International Journal of Obstetrics \& Gynaecology, 115, 1171-1178. 
GRIMES, D. A., BENSON, J., SINGH, S., ROMERO, M., GANATRA, B., OKONOFUA, F. E. \& SHAH, I. H. 2006. Unsafe abortion: the preventable pandemic. The Lancet, 368, 1908-1919.

GUTTMACHER INSTITUTE 2013. Unintended Pregnancy and Abortion in Uganda. In Brief. New York: Guttmacher Institute.

GUTTMACHER INSTITUTE \& IBIS REPRODUCTIVE HEALTH 2013. Using Research to Make the Case for Investments in Safe Abortion Care.

HARRIES, J., COOPER, D., STREBEL, A. \& COLVIN, C. J. 2014. Conscientious objection and its impact on abortion service provision in South Africa: a qualitative study. Reproductive Health, 11, 1-7.

HATCHER, R. A. 2007. Contraceptive technology, New York, Ardent Media.

HODOROGEA, S. \& COMENDANT, R. 2010. Prevention of unsafe abortion in countries of Central Eastern Europe and Central Asia. International Journal of Gynecology \& Obstetrics, 110, Supplement, S34-S37.

HUKIN, E. F. 2012. Contraception in Cambodia: Explaining Unmet Need. $\mathrm{PhD}$, London School of Economics and Political Science.

JAGWE-WADDA, G., MOORE, A. M. \& WOOG, V. 2006. Abortion Morbidity in Uganda: Evidence from Two Communities. Occasional Report. New York: Guttmacher Institute.

JEWKES, R. K., GUMEDE, T., WESTAWAY, M. S., DICKSON, K., BROWN, H. \& REES, H. 2005. Why are women still aborting outside designated facilities in metropolitan South Africa? BJOG: An International Journal of Obstetrics \& Gynaecology, 112, 1236-1242.

JOHNSON-HANKS, J. 2002. The lesser shame: abortion among educated women in southern Cameroon. Social Science \&amp; Medicine, 55, 1337-1349.

JONES, R. K., UPADHYAY, U. D. \& WEITZ, T. A. 2013. At What Cost? Payment for Abortion Care by U.S. Women. Women's Health Issues, 23, e173-e178.

KAVANAUGH, M. L., BESSETT, D., LITTMAN, L. L. \& NORRIS, A. 2013a. Connecting Knowledge about Abortion and Sexual and Reproductive Health to Belief about Abortion Restrictions: Findings from an Online Survey. Women's Health Issues, 23, e239-e247.

KAVANAUGH, M. L., MOORE, A. M., AKINYEMI, O., ADEWOLE, I., DZEKEDZEKE, K., AWOLUDE, O. \& ARULOGUN, O. 2013b. Community attitudes towards childbearing and abortion among HIV-positive women in Nigeria and Zambia. Culture, health \& sexuality, 15, 160-174.

LAFARGE, C., MITCHELL, K. \& FOX, P. 2013. Women's experiences of coping with pregnancy termination for fetal abnormality. Qual Health Res, 23, 924-36.

LAMAS, M. \& BISSELL, S. 2000. Abortion and politics in Mexico: 'context is all'. Reproductive Health Matters, 8, 10-23.

LEVANDOWSKI, B. A., KALILANI-PHIRI, L., KACHALE, F., AWAH, P., KANGAUDE, G. \& MHANGO, C. 2012. Investigating social consequences of unwanted pregnancy and unsafe abortion in Malawi: The role of stigma. International Journal of Gynecology and Obstetrics, 118, S167-S171.

LEVIN, C., GROSSMAN, D., BERDICHEVSKY, K., DIAZ, C., ARACENA, B., GARCIA, S. G. \& GOODYEAR, L. 2009. Exploring the costs and economic consequences of unsafe abortion in Mexico City before legalisation. Reproductive Health Matters, 17, 120-132.

LOHR, P. A., FJERSTAD, M., DESILVA, U. \& LYUS, R. 2014. Abortion.

MACLEOD, C., SIGCAU, N. \& LUWACA, P. 2011. Culture as a discursive resource opposing legal abortion. Critical Public Health, 21, 237-245. 
MACQUARRIE, K., EDMEADES, J., MACAULAY, C., NYBLADE, L. \& MALHOTRA, A. 2007. Women, Husbands, and In-Laws: Abortion Decision-Making in Madhya Pradesh, India. Population Association of America 2007 Annual Meeting. New York, NY.

MARLOW, H. M., SHELLENBERG, K. \& YEGON, E. 2014. Abortion services for sex workers in Uganda: successful strategies in an urban clinic. Culture, Health \& Sexuality, 1-13.

MCMURTRIE, S. M., GARCIA, S. G., WILSON, K. S., DIAZ-OLAVARRIETA, C. \& FAWCETT, G. M. 2012. Public opinion about abortion-related stigma among Mexican Catholics and implications for unsafe abortion. international Journal of Gynecology and Obstetrics, 118, S160-S166.

MILES, M. B. \& HUBERMAN, A. M. 1994. Qualitative data analysis : an expanded sourcebook, Thousand Oaks, Calif. ; London, Sage.

MOORE, A. M., FROHWIRTH, L. \& MILLER, E. 2010. Male reproductive control of women who have experienced intimate partner violence in the United States. Social Science \& Medicine, 70, 1737-44.

MOORE, A. M., JAGWE-WADDA, G. \& BANKOLE, A. 2006. Men's attitudes about abortion in Uganda. Journal of Biosocial Science, 43, 1-15.

MOORE, A. M., KIBOMBO, R. \& CATS-BARIL, D. 2013. Ugandan opinion-leaders' knowledge and perceptions of unsafe abortion. Health Policy and Planning, [Advance Access published], 1-9.

MOORE, A. M., SINGH, S. \& BANKOLE, A. 2011. Do women and men consider abortion as an alternative to contraception in the United States? An exploratory study. Global Public Health, 6 Suppl 1, S25-37.

MORHE, R. A. S., MORHE, E. S. K. \& DANSO, K. A. 2007. Attitudes of doctors toward establishing safe abortion units in Ghana. International Journal of Gynecology and Obstetrics, 98, 70-74.

MPANGILE, G. S., LESHABARI, M. T., KAAYA, S. \& KIHWELE, D. 1998. Abortion and unmet need for contraception in Tanzania-the role of male partners in teenage induced abortion in Dar Es Salaam. African Journal of Reproductive Health, 2, 108-121.

NGO, T. D., KEOGH, S., NGUYEN, T. H., LE, H. T., PHAM, K. H. T. \& NGUYEN, Y. B. T. 2014. Risk factors for repeat abortion and implications for addressing unintended pregnancy in Vietnam. International Journal of Gynecology \& Obstetrics, 125, 241246.

NORRIS, A., BESSETT, D., STEINBERG, J. R., KAVANAUGH, M. L., DE ZORDO, S. \& BECKER, D. 2011. Abortion stigma: a reconceptualization of constituents, causes, and consequences. Womens Health Issues, 21, S49-54.

NORRIS, A., HEMED, M. \& CASTERLINE, J. 2014. Fears of unwanted pregnancy versus fears of unsafe abortion: A qualitative community-based study with women who terminated pregnancies in Zanzibar, Tanzania. International Union for the Scientific Study of Population International Seminar on Decision-Making Regarding Abortion Determinants and Consequences. Nanyuki, Kenya.

OKONTA, P. I., EBEIGBE, P. N. \& SUNDAY-ADEOYE, I. 2010. Liberalization of abortion and reduction of abortion related morbidity and mortality in Nigeria. ACTA OBSTETRICIA ET GYNECOLOGICA SCANDINAVICA, 89, 1087-1090.

ORNER, P., DE BRUYN, M. \& COOPER, D. 2011. 'It hurts, but I don't have a choice, I'm not working and I'm sick': decisions and experiences regarding abortion of women living with HIV in Cape Town, South Africa. Culture, Health \& Sexuality, 13, 781. 
ORNER, P., DE BRUYN, M., HARRIES, J. \& COOPER, D. 2010. A qualitative exploration of HIV-positive pregnant women's decision-making regarding abortion in Cape Town, South Africa. SAHARA J-JOURNAL OF SOCIAL ASPECTS OF HIV-AIDS, 7, 44-51.

PATEL, L., BENNETT, T. A., HALPERN, C. T., JOHNSTON, H. B. \& SUCHINDRAN, C. M. 2009. Support for provision of early medical abortion by mid-level providers in Bihar and Jharkhand, India. Reproductive Health Matters, 17, 70-79.

PAYNE, C. M., PRECOURT DEBBINK, M., STEELE, E. A., BUCK, C. T., MARTIN, L. A., HASSINGER, J. A. \& HARRIS, L. H. 2013. Why Women are dying from unsafe Abortion: Narratives of Ghanaian abortion providers. Afr J Reprod Health, 17, 118128.

RALPH, L., GOULD, H., BAKER, A. \& FOSTER, D. G. 2014. The Role of Parents and Partners in Minors' Decisions to Have an Abortion and Anticipated Coping After Abortion. Journal of Adolescent Health, 54, 428-434.

RAMACHANDAR, L. \& PELTO, P. J. 2002. The Role of Village Health Nurses in Mediating Abortions in Rural Tamil Nadu, India. Reproductive Health Matters, 10, 64-75.

REICHEL, M. \& RAMEY, M. A. 1987. Conceptual frameworks for bibliographic education : theory into practice, Littleton, Colo., Libraries Unlimited.

ROMINSKI, S. D., GUPTA, M., ABORIGO, R., ADONGO, P., ENGMAN, C., HODGSON, A. \& MOYER, C. 2014. Female autonomy and reported abortion-seeking in Ghana, West Africa. Int J Gynaecol Obstet.

ROSSIER, C. 2007. Abortion: an open secret? Abortion and social network involvement in Burkina Faso. Reproductive Health Matters, 15, 230-238.

SÁNCHEZ FUENTES, M. L., PAINE, J. \& ELLIOTT-BUETTNER, B. 2008. The decriminalisation of abortion in Mexico City: how did abortion rights become a political priority? Gender \& Development, 16, 345-360.

SCHUSTER, S. 2005. Abortion in the Moral World of the Cameroon Grassfields. Reproductive Health Matters, 13, 130-138.

SCHWANDT, H. M., CREANGA, A. A., ADANU, R. M., DANSO, K. A., AGBENYEGA, T. \& HINDIN, M. J. 2013. Pathways To Unsafe Abortion In Ghana: The Role Of Male Partners, Women, And Health Care Providers. Contraception.

SEDGH, G. \& HUSSAIN, R. 2014. Reasons for Contraceptive Nonuse among Women Having Unmet Need for Contraception in Developing Countries. Studies in Family Planning, 45, 151-169.

SEDGH, G., ROSSIER, C., KABORÉ, I., BANKOLE, A. \& MIKULICH, M. 2011. Estimating abortion incidence in Burkina Faso using two methodologies. Studies in family planning, 42, 147-154.

SHELLENBERG, K. M. \& TSUI, A. O. 2012. Correlates of perceived and internalized stigma among abortion patients in the USA: An exploration by race and Hispanic ethnicity. International Journal of Gynecology and Obstetrics, 118, S152-S159.

SINGH, S., WULF, D. \& JONES, H. 1997. Health Professionals' Perceptions About Induced Abortion in South Central and Southeast Asia. International Family Planning Perspectives, 23, 59-72.

SMITH, R. 2004. Exploring the Usefulness of a Conceptual Framework as a Research Tool: A Researcher's Reflections. Issues in Educational Research, 14, 167-180.

SOWMINI, C. V. 2013. Delay in termination of pregnancy among unmarried adolescents and young women attending a tertiary hospital abortion clinic in Trivandrum, Kerala, India. Reproductive Health Matters, 21, 243-250. 
TAGOE-DARKO, E. 2013. "Fear, Shame and Embarrassment": The Stigma Factor in Post Abortion Care at Komfo Anokye Teaching Hospital, Kumasi, Ghana. Asian Social Science, 9, p134.

TARACENA, R. 2002. Social Actors and Discourse on Abortion in the Mexican Press: the Paulina Case. Reproductive Health Matters, 10, 103-110.

THAPA, S., SHARMA, S. K. \& KHATIWADA, N. 2014. Women's knowledge of abortion law and availability of services in Nepal. Journal of Biosocial Science, 46, 266-277.

TONG, W., LOW, W., WONG, Y., CHOONG, S. \& JEGASOTHY, R. 2012. Exploring pregnancy termination experiences and needs among Malaysian women: A qualitative study. BMC Public Health, 12, 743.

UGANDA BUREAU OF STATISTICS (UBOS) \& ICF INTERNATIONAL 2012. Uganda Demographic and Health Survey 2011. Kampala, Uganda and Calverton, MD, USA: ICF International.

VÄISÄNEN, H. \& MURPHY, M. 2014. Social Inequalities in Teenage Fertility Outcomes: Childbearing and Abortion Trends of Three Birth Cohorts In Finland. Perspectives on Sexual and Reproductive Health, n/a-n/a.

VALA-HAYNES, E. \& ROCHAT, R. W. 2007. Abortion-Politics and Media in Mexico. Population Association of America 2007 Annual Meeting. New York, NY.

WATSON, K. 2014. Reframing regret. JAMA, 311, 27-28.

WEBSTER, N. 2013. Unsafe abortion: regulation of the social body even beyond time and space. Culture, Health \& Sexuality, 15, 358-371.

ZAMBERLIN, N., ROMERO, M. \& RAMOS, S. 2012. Latin American women's experiences with medical abortion in settings where abortion is legally restricted. Reprod Health, 22, 1 . 